\title{
River plumes of the Great Barrier Reef: freshwater, sediment and optical footprints quantified by the eReefs modelling system
}

\author{
$\underline{\text { M. Baird }}^{\text {a }}$, J. Andrewartha ${ }^{\text {a }}$, M. Herzfeld ${ }^{\text {a }}$, E. Jones ${ }^{\text {a }}$, N. Margvelashvili ${ }^{\text {a }}$, M. Mongin ${ }^{\text {a }}$, F. Rizwi ${ }^{\text {a }}$, \\ J. Skerratt $^{\text {a }}$, M. Soja-Wozniak ${ }^{\text {a }}$, K. Wild-Allen ${ }^{\text {a }}$, T. Schroeder ${ }^{\text {b }}$, B. Robson ${ }^{\text {c }}$, E. da Silva ${ }^{\text {d }}$, M. Devlin ${ }^{\text {e }}$ \\ ${ }^{a}$ CSIRO Oceans and Atmosphere, GPO Box 1538, Hobart, TAS 7001 \\ ${ }^{b}$ CSIRO Oceans and Atmosphere, 41 Boggo Road, Dutton Park, QLD 4102 \\ ${ }^{c}$ CSIRO Land and Water, GPO Box 1700, Canberra, ACT 2601 \\ ${ }^{d}$ Centre for Tropical Water and Aquatic Ecosystem Research, Catchment to Reef Research Group, James \\ Cook University, Townsville, QLD 4811 \\ ${ }^{e}$ Centre for Environment, Fisheries and Aquaculture Science, Lowestoft Suffolk NR33 0HT, UK \\ Email: Mark.Baird@csiro.au
}

\begin{abstract}
The rivers of the northeast coast of Australia flow into the coastal and shelf regions of the Great Barrier Reef (GBR), delivering high loads of nutrients, sediments and freshwater during the wet season period. A significant component of the loads come from anthropogenic activities. These river plumes impact on marine environments through exposure to low salinity and high pesticide concentration seawater, and increased attenuation of light as a result of terrestrially-derived colour dissolved organic matter (CDOM), suspended sediments and phytoplankton. A coupled hydrodynamic, sediment, optical and biogeochemical model of the GBR (eReefs) provides a new means to quantify the multiple impacts of river plumes. In this paper, the spatial and temporal extent of freshwater plumes are calculated using the release of river tracers from 21 rivers along the Queensland coast in the first six months of 2016. To quantify the sediment plume extent, we use a threshold of $1 \mathrm{mg} \mathrm{L}^{-1}$ surface suspended sediment concentrations. Past observational studies have quantified optical plumes along the GBR using changing ocean colour. We use the eReefs optical model capability of simulating remote-sensing reflectance from simulated optically-active in-water properties (e.g. sediment concentration) to provide a quantification of the footprint of optical plumes. Simulated optical plumes are classified using the same scheme developed for remotely-sensed optical plumes, providing the opportunity to assess simulated plume classification against the observed plume classifications. Snapshots on a relatively cloud-free day of the observed plume classes and observed true colour, and of the simulated plume classes and simulated true colour, show that the model captures the broad regions of colour, and therefore plume classification.
\end{abstract}

A comparison of different methods of plume identification in the Burdekin plume during a high discharge event illustrates complexities of quantifying plume extent. The river tracer shows the distribution of Burdekin River water, with a plume extending to $\sim 7 \mathrm{~km}$ offshore, in a roughly $5 \mathrm{~m}$ deep surface flow. The shape of the freshwater plume is similar, although during periods of evaporation / rainfall it becomes difficult to distinguish individual plumes from salinity alone. The optical plume classifications correspond well to the river tracer and freshwater plumes within the actual plume, but result in plume identifications outside the actual plume due to tidal and wind-driven resuspension and bottom reflectance.

The river discharge, as well as the river tracer, freshwater, sediment and optical plume extents were quantified for the wet season of 2016. The strongest mean river discharge came, in decreasing order, from the Fitzroy, Normanby, Burdekin and Tully rivers. The freshwater footprints were slightly re-ordered, with the largest spatial extents of the Normanby, Fitzroy, Burdekin and Tully. The Fitzroy had easily the largest sediment plume, followed by the Pioneer. In summary, through considering freshwater, sediment and optical plumes of the major rivers, we provide a comprehensive view of the footprint of terrestrially-derived loads on the marine waters of the GBR.

Keywords: Ocean colour, catchment loads, suspended sediment, chlorophyll 


\section{INTRODUCTION}

The iconic Great Barrier Reef (GBR), a $2000 \mathrm{~km}$ coral reef system off the northeast coast of Australia, has faced recent declines in coral cover (De'ath et al., 2009) and seagrass extent (Collier et al., 2012). Declining water quality from land-based runoff is one of the most significant threats to the health of the GBR, with sediments, nutrients, and pesticides identified as the key contaminants of concern. On average, $70 \mathrm{~km}^{3}$ of freshwater is discharged each year by rivers and streams into the GBR lagoon (Devlin et al., 2015).

To manage water quality on the GBR it is necessary to quantify the spatial footprint of river plumes and the changes in water quality they drive, but all available methods have drawbacks. The task of monitoring the plume from a flood event in the vicinity of the river mouth using in situ observations is possible (Devlin et al., 2015), but determining the mean impact of plumes along the entire Queensland coast over seasonal timescales using in situ observations is impossible. Optical plumes can be tracked in near-real-time using satellite remote-sensing (Schroeder et al., 2012), but observations are often obscured by clouds, especially in the wet season, and it is not always possibly to distinguish individual river plumes. Finally, tracer experiments using a skilful hydrodynamic model perfectly delineates individual plumes footprints, but tracer distributions depend strongly on uncertain river discharge estimates, and are themselves essentially untestable (Brinkman et al., 2014). Thus while a number of approaches to quantifying plumes exist, inherent limits have frustrated the ability to provide a comprehensive view.

In this paper we provide estimates of freshwater, sediment and optical plume extents from 16 rivers discharging into the GBR using the coupled eReefs hydrodynamic / optical / sediment / biogeochemical model. As well as providing a comprehensive model view, this analysis provides insights into the differing characteristics of the existing observational plume quantification methods.

\section{MODEL}

\section{1 eReefs marine modelling}

The eReefs coupled hydrodynamic, optical, sediment and biogeochemical model has been configured at $\sim 1$ $\mathrm{km}$ resolution for the northeast Australian continental shelf, from $28^{\circ} 40^{\prime} \mathrm{S}$ to the Papua New Guinea coastline. More details on the model grid and hydrodynamic configuration are given in Herzfeld and Gillibrand (2015) and Herzfeld (2015). The sediment (Margvelashvili et al., 2016), optical (Baird et al., 2016) and biogeochemical (Mongin et al., 2016) models are similarly described in detail, with a further 600+ pages documenting model configuration and skill assessment available at www . eReefs. info (Herzfeld et al., 2016).

The model is forced using flow and concentrations of dissolved and particulate constituents from 21 rivers along the Queensland coast (north to south: Normanby, Daintree, Barron, combined Mulgrave+Russell, Johnstone, Tully, Herbert, Haughton, Burdekin, Don, O’Connell, Pioneer, Fitzroy, Burnett, Mary, Calliope, Boyne, Caboolture, Pine, combined Brisbane+Bremer, and combined Logan+Albert) and the Fly River in Papua New Guinea. River concentrations of sediment and nutrient were based on mean values from observations over a 10 year period (Furnas, 2003). Separate means were obtained for wet- (the Fly, and the northern most 6 rivers in Queensland) and dry- (remainder) catchment rivers, and multiplied by guaged flows to obtain river loads.

The model uses a novel river boundary condition (Herzfeld, 2015) that discharges the river freshwater load in a brackish surface plume whose salinity and thickness is calculated to account for upstream flow in the salt wedge and in-estuary mixing between density layers. This is most important when a salt wedge exists; under high flow, when the river mouth salinity is zero, the boundary condition is similar to direct freshwater discharge into the ocean. Herzfeld (2015) shows this boundary condition provides realistic plume dynamics, in particular avoiding excessive offshore transport due to overestimating the density difference between the plume and oceanic waters.

\subsection{Tracking of river plumes}

The footprint of individual rivers can be calculated using conservative tracers. In this paper, we use a tracer with a unit concentration (say $1 \mathrm{~kg} \mathrm{~m}^{-3}$ ) in the river flow, resulting in a tracer load proportional to the flow. Thus a location with 0.5 concentration will be composed of $50 \%$ river water, and $50 \%$ water either from another river, or oceanic. The tracer is advected and diffused using a conservation flux-form scheme based on hourly-averaged 3D velocity fields (Gillibrand and Herzfeld, 2016). Sediment and optical plumes are defined for each river only within the $1 \%$ tracer footprint. The simulation began tracking plumes on 1 Dec 2014. 


\subsection{Optical plume classification}

Optical properties have been used to classify the extent of plumes (Devlin et al., 2013, 2015). Here we use a similar approach on simulated optical plumes. First we determine from observations the spectra of 6 standard plume classes as adopted by Devlin et al. (2015). Using these standard plume classifications, we determine the dissimilarity, $S(c)$, between an observed or simulated spectra and the spectra of each standard class $c$ as a sum of the square of the difference: $S(c)=\sum_{\lambda=1}^{W}\left(R_{r s, c, \lambda}-R_{r s, s i m, \lambda}\right)^{2}$ where $R_{r s, c, \lambda}$ is the remotesensing reflectance of class $c$ at wavelength $\lambda, R_{r s, s i m, \lambda}$ is the remote-sensing reflectance of the simulation at wavelength $\lambda$ and $W$ is the number of wavelengths considered. The observed or simulated spectra is then assigned to the standard class $c$ with the minimum dissimilarity, $S$, between the standard class and the observed or simulated spectra.

Simulated true colour. Just as observed true colour images are generated from satellite remote-sensing reflectance, simulated true colour images can be generated from simulated remote-sensing reflectance in the red, green and blue wavebands (Baird et al., 2016). We have adopted the processing techniques used to produce MODIS true colour images described in Gumley et al. (2010): true colour image brightness (on a scale of black $=0$, white $=1$ ) is adjusted by linearly mapping remote-sensing reflectance at each of the three wavelengths to a brightness that approaches 1 in the brightest of the three bands. Additionally, a piece-wise linear scaling is used to brighten dark components. Thus, simulated true colour is determined from combining simulated remote-sensing reflectance using the techniques developed for processing remotely-sensed true colour.

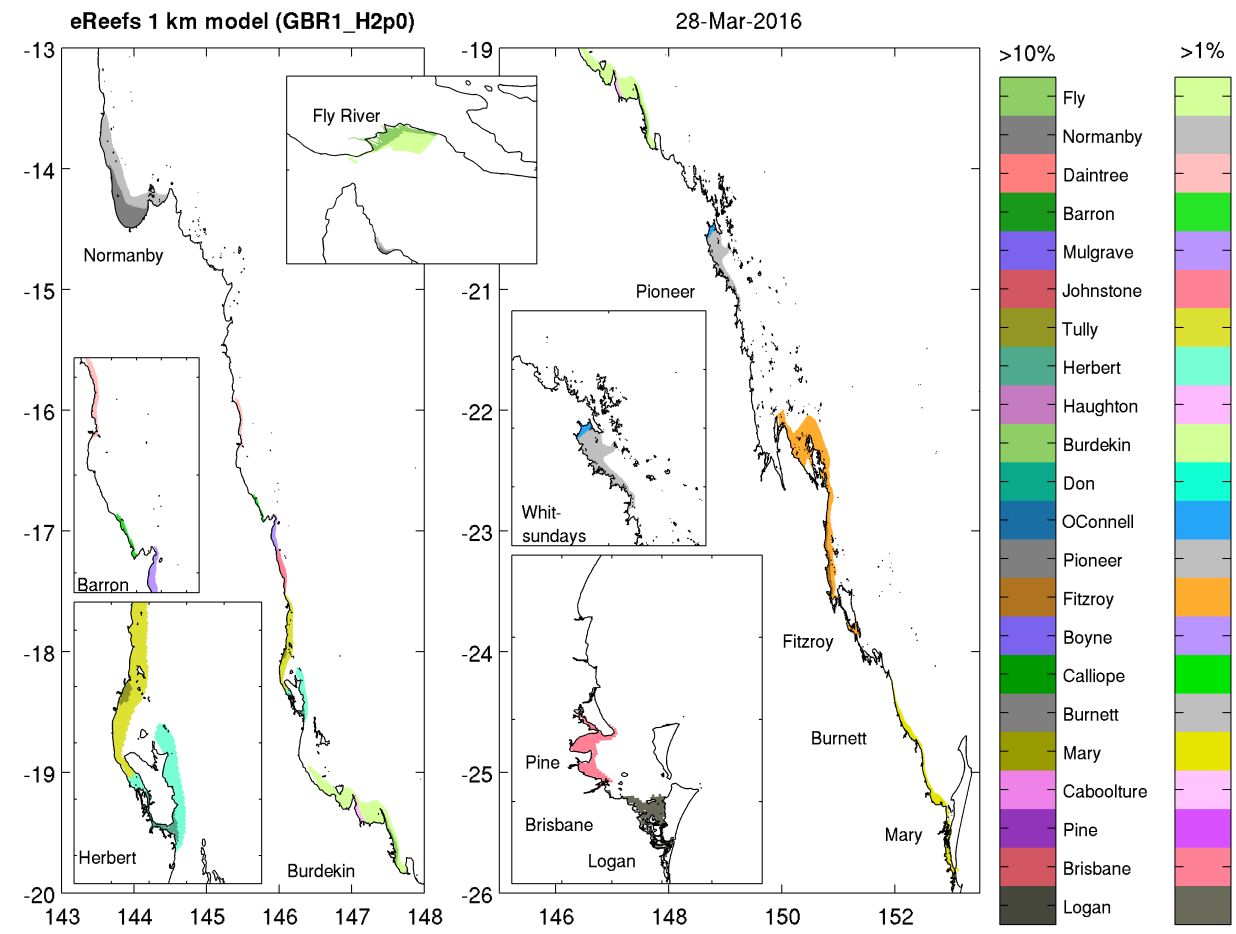

Figure 1. River plume extents on 28 March 2016. For each river, two hues are given. The darker repre-sents locations where greater than $10 \%$ of the water is from a particular river, while the lighter hue represent between 10 and $1 \%$. Where no river exceeds $1 \%$, the ocean appears white. If water at a particular lo-cation contains multiple river waters, only the higher concentration plume is shown.

Animation of 2016 at WWW. eReefs. info.

\section{RESULTS AND DISCUSSION}

The spatial extent of all 22 rivers on the 28 March 2016, the greatest average plume extent seen in 2016, is shown in Fig. 1. At this time the Normanby, Tully, Herbert, Burdekin and Pioneer rivers had the greatest 

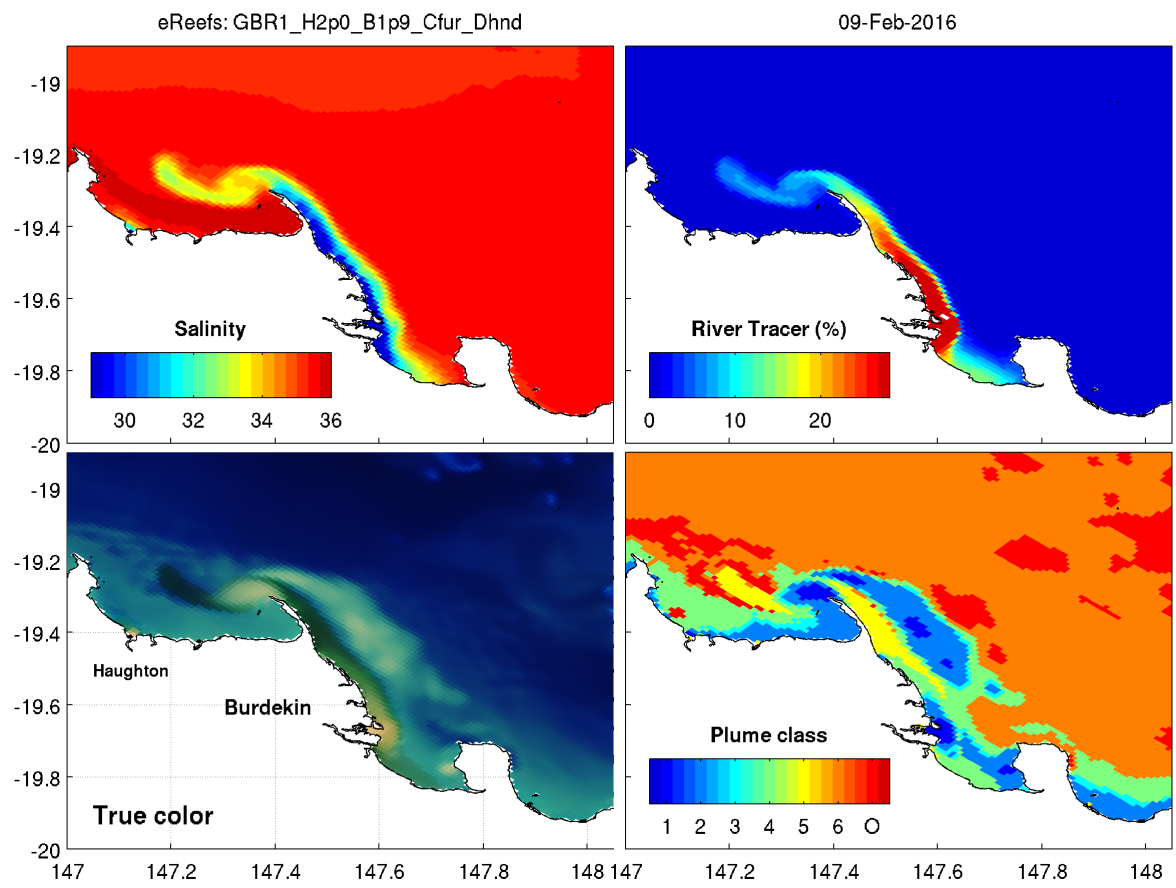

Figure 2. The Burdekin River plume at midday on the 9 February 2016 in eReefs simulation GBR1_H2p0_B1p9_Cfur_Dhnd, as quantified, clockwise from top left by, surface salinity, surface Burdekin tracer, optical plume classification, and simulated true colour. Animation of 2016 at www . eReefs. info.

freshwater footprints. All river plumes are deflected to the left due to the Earth's rotation, and move northward. Plumes extents are determined by mixing that dilutes the river tracer concentration below $1 \%$. Interestingly, an animation of 2016 shows that Fitzroy water that has moved north to between Shoalwater Bay and Repulse Bay and resides for months before being mixed with the main GBR lagoon waters, demonstrating that the impact of plumes on water quality can last for seasons (www. eReefs. info).

The different methods of plume identification can be compared for the Burdekin plume during a high discharge $\left(\sim 1300 \mathrm{~m}^{3} \mathrm{~s}^{-1}\right)$ event in early February 2016 (Fig. 2). The river tracer shows the distribution of Burdekin River water, with a plume extending to $\sim 7 \mathrm{~km}$ offshore, in a roughly $5 \mathrm{~m}$ deep (not shown) surface flow. The shape of the freshwater plume is similar to the tracer distribution, although it is important to note a small freshwater signal from the Haughton River. Under less dramatic flows, and during periods of evaporation /rainfall, it becomes difficult to distinguish individual plumes from salinity alone.

The simulated true colour image shows the plume exiting as a dark brown bulge (Fig. 2), classified as a plume class one (PC1). Following the plume downstream, as it is trapped against the coast, the sediments sink leading to a quick transformation through PC2, PC3 and PC4. By 30-40 km downstream, the sediments have sunk below the optical depth for red (Margvelashvili et al., 2016), and the water is primarily influenced by dark green coloured dissolved organic matter (PC5, CDOM). Interestingly as the flow passes Cape Bowling Green, resuspension entrains particles into the flow, and waters return to $\mathrm{P} \mathrm{C1}$. After the sediments a gain sink, the waters are back to PC5.

While the simulated plume classification did a good job within the plume, a number of false plume identifications are seen. Firstly the shallow waters in the three northward facing bays appear light green, with some classifications of PC1, despite not being directly exposed to the p lume. This will be due to a combination of earlier residual plume waters, and in the shallowest cases, the bottom reflectance. Offshore of the plume there is a large region of light brown, PC1 waters. The 9 February 2016 also corresponded to a new moon and a low pressure system $(998 \mathrm{kPa})$ in the adjacent Coral Sea, resulting in resuspension on the mid-shelf. Finally, it is worth noting that offshore reefs (visible as a light blue in the northeast corner of the true colour image), register as oceanic waters, in an otherwise PC6 continental shelf waters. At other times (not shown), resuspension on offshore reefs can result in a PC1 classification. 
Comparison with observations. A thorough skill assessment of the model is undertaken elsewhere (Herzfeld et al., 2016). A single snapshot of the observed plume classes and true colour (Fig. 3 top) and simulated plume classes and true colour (Fig. 3 bottom) on a relatively cloud-free day shows that the model captures the broad regions of colour, and therefore plume classification. Interestingly the coarser resolution of the satellite (up to $2 \mathrm{~km}$ on this section of the swath) results in mis-identification of plume classes on some plume fronts, while the higher resolution simulated plume classes present a more coherent front.

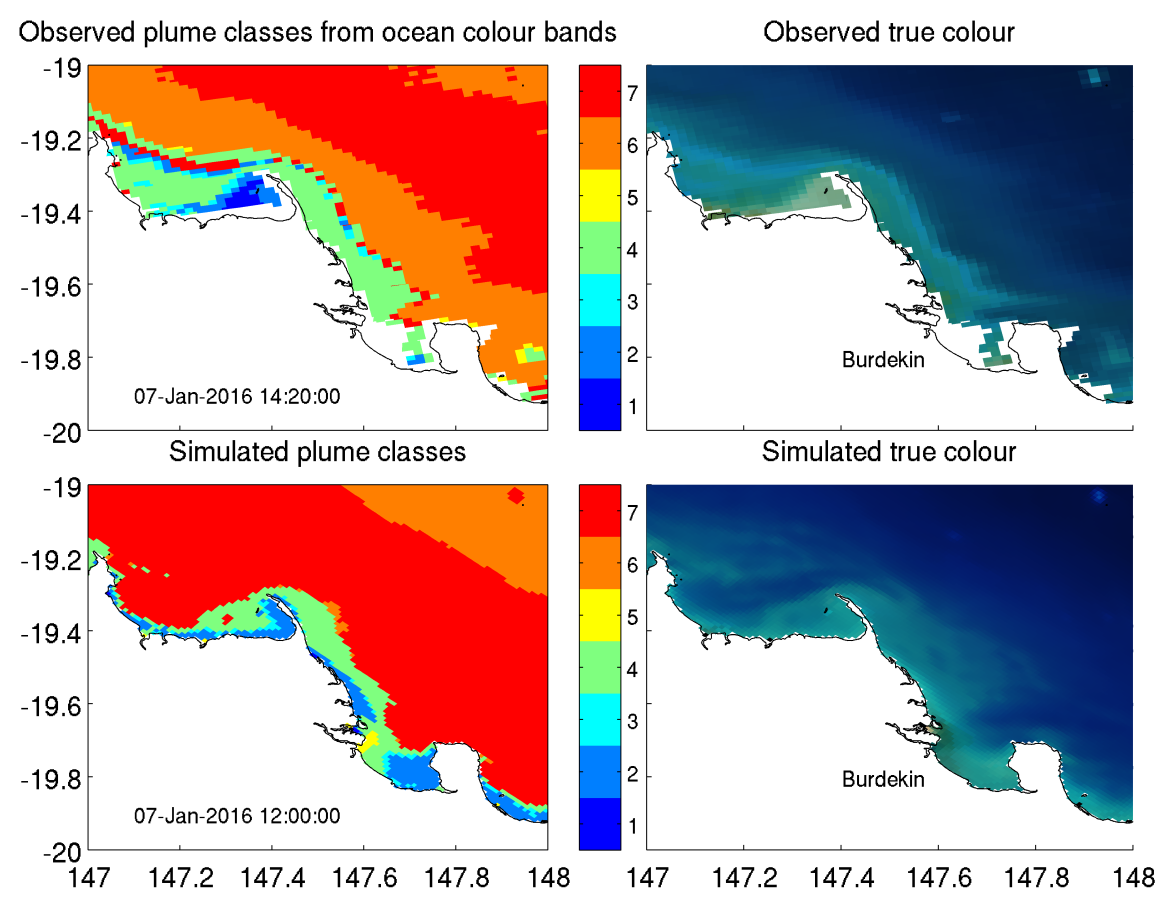

Figure 3. The Burdekin plume at midday on the 7 January 2016 visualised as the observed plume classification and observed true colour (top), and simulated plume classification and simulated true colour (bottom). To align with atmospherically-corrected remote-sensing reflectance, true colour used 488, 547 and 667 wavelengths.

Footprints for 2016 wet season. For the six months of 1 Dec 2015 - 31 May 2016, the strongest mean discharge $\left[\mathrm{m}^{3} \mathrm{~s}^{-1}\right]$ came, in decreasing order, from the Fitzroy (220), Normanby (144), Burdekin (99) and Tully (98) rivers (Table 1). The freshwater footprints were slightly re-ordered, with spatial extents $\left[\mathrm{km}^{2}\right] \mathrm{of}^{2}$ Normanby (2373), Fitzroy (1191), Burdekin (1545) and Tully (645). The Normanby obtains the greatest freshwater plume extent (as measured by the $1 \%$ tracer contour) as a result of retention within Princess Charlotte Bay. The sediment and optical plumes extents are limited to those areas within the freshwater plumes, to avoid erroneous identification of oceanic resuspension-driven colour changes. The Fitzroy has easily the largest sediment plume $\left(53 \mathrm{~km}^{2}\right)$, followed by the Pioneer $\left(17 \mathrm{~km}^{2}\right)$. This is in part due to the greater concentration in the model of discharge of inorganic suspended sediments in dry $\left(0.231 \mathrm{~kg} \mathrm{~m}^{-3}\right)$ versus wet $\left(0.066 \mathrm{~kg} \mathrm{~m}^{-3}\right)$ tropical rivers (Furnas, 2003), and also greater resuspension in the south within freshwater plume extents. The largest PC1 plume was the Normanby (306), closely followed by the Fitzroy (261) and Mary (253). PC1 is assumed to be a result of surface sediment plumes, which is true of the Fitzroy. The Normanby and Mary registered with high PC1 plume extents as a result of the plume classification algorithm matching surface sediment plume colour with bottom reflectance from optically-shallow regions.

Conclusions. The quantification of river plumes of the GBR demonstrated that using salinity, sediment or water clarity as measures of plume extent produces differing views of the influence of terrestrial discharge on the coastal ocean. In the wet season of 2016 on the GBR, the Normanby freshwater plume covered the greatest spatial extent, but the Fitzroy, due to greater discharge and high suspended sediment load, had the widest influence on water quality, as measured by suspended sediment concentration and water clarity. 
Table 1. Mean and (maximum) discharge, as well as freshwater (tracer $>1 \%)$, sediment $(\mathrm{TSS}>1 \mathrm{mg} \mathrm{L}-1$ and tracer $>1 \%$ ) and plume class footprints (tracer $>1 \%$, and labelled PC1-PC6, $\mathrm{km}^{2}$ ) of 16 rivers impacting the GBR between 1 Dec 2015 and 31 May 2016. The minimum footprint for the 6 months in each class is generally less than the $1 \mathrm{~km}^{2}$, and therefore below detection for the $1 \mathrm{~km}$ model. The $1 \mathrm{st}$, 2nd and 3rd largest mean discharge and footprints are shaded.

\begin{tabular}{|c|c|c|c|c|c|c|c|c|c|}
\hline & \multirow{2}{*}{$\begin{array}{c}\text { River } \\
\text { Discharge } \\
{\left[\mathrm{m}^{3} \mathrm{~s}^{-1}\right]} \\
\end{array}$} & \multicolumn{8}{|c|}{ Footprint } \\
\hline & & $\begin{array}{c}\text { Freshwater } \\
{\left[\mathrm{km}^{2}\right]}\end{array}$ & $\begin{array}{c}\text { Sediment } \\
{\left[\mathrm{km}^{2}\right]}\end{array}$ & $\begin{array}{c}\mathrm{PC} 1 \\
{\left[\mathrm{~km}^{2}\right]} \\
\end{array}$ & $\begin{array}{c}\mathrm{PC} 2 \\
{\left[\mathrm{~km}^{2}\right]} \\
\end{array}$ & $\begin{array}{c}\mathrm{PC} 3 \\
{\left[\mathrm{~km}^{2}\right]} \\
\end{array}$ & $\begin{array}{c}\mathrm{PC} 4 \\
{\left[\mathrm{~km}^{2}\right]} \\
\end{array}$ & $\begin{array}{c}\text { PC5 } \\
{\left[\mathrm{km}^{2}\right]} \\
\end{array}$ & $\begin{array}{c}\text { PC6 } \\
{\left[\mathrm{km}^{2}\right]} \\
\end{array}$ \\
\hline \multirow[t]{2}{*}{ "Normanby } & 144 & 2373 & 9 & 306 & 528 & 131 & 811 & 194 & 118 \\
\hline & $(823)$ & $(5152)$ & (46) & (3057) & (2418) & $(475)$ & (2119) & (1156) & (696) \\
\hline \multirow[t]{2}{*}{ Daintree } & 51 & 79 & 4 & 3 & 4 & 1 & 7 & 44 & 17 \\
\hline & (746) & (1218) & (28) & (29) & (18) & (5) & (38) & (781) & (633) \\
\hline \multirow[t]{2}{*}{ Barron } & 13 & 43 & 4 & 15 & 11 & 1 & 7 & 5 & 1 \\
\hline & $(425)$ & (506) & (22) & (58) & (76) & (14) & (157) & (157) & (146) \\
\hline Russell- & 44 & 147 & 7 & 5 & 8 & 2 & 22 & 77 & 15 \\
\hline Mulgrave & (261) & (1289) & (31) & (124) & (53) & (24) & (124) & $(821)$ & (410) \\
\hline \multirow[t]{2}{*}{ Johnstone } & 59 & 182 & 8 & 3 & 8 & 3 & 23 & 87 & 29 \\
\hline & (414) & (1535) & (37) & (94) & (59) & (16) & (107) & (494) & (1285) \\
\hline \multirow[t]{2}{*}{ Tully } & 98 & 645 & 11 & 31 & 118 & 23 & 132 & 264 & 26 \\
\hline & (495) & (2422) & (83) & (444) & (293) & $(60)$ & (362) & (1214) & (972) \\
\hline \multirow[t]{2}{*}{ Herbert } & 53 & 325 & 4 & 32 & 85 & 14 & 91 & 92 & 8 \\
\hline & (1071) & (1185) & (46) & (112) & (179) & (56) & (390) & (733) & (393) \\
\hline \multirow[t]{2}{*}{ Haughton } & 7 & 60 & 3 & 1 & 17 & 5 & 23 & 13 & 0 \\
\hline & (140) & (177) & (10) & (4) & (61) & (17) & (67) & (151) & (3) \\
\hline \multirow{2}{*}{ Burdekin } & 99 & 1545 & 10 & 33 & 434 & 136 & 544 & 131 & 58 \\
\hline & (2282) & (3684) & (94) & (518) & (1388) & $(546)$ & (1754) & (1080) & (1260) \\
\hline \multirow[t]{2}{*}{ Don } & 2 & 3 & 1 & 0 & 2 & 0 & 0 & 1 & 0 \\
\hline & (228) & (66) & (12) & (7) & (37) & (5) & (16) & (2) & (0) \\
\hline \multirow[t]{2}{*}{ OConnell } & 7 & 23 & 2 & 6 & 3 & 1 & 8 & 5 & 0 \\
\hline & (229) & (152) & (26) & (63) & (33) & (14) & (91) & (96) & (0) \\
\hline \multirow[t]{2}{*}{ Pioneer } & 38 & 306 & 17 & 72 & 94 & 12 & 55 & 25 & 1 \\
\hline & (1422) & (1242) & (216) & (430) & (530) & (103) & (519) & (332) & (19) \\
\hline \multirow{2}{*}{ Fitzroy } & 220 & 1911 & 53 & 261 & 523 & 79 & 359 & 98 & 53 \\
\hline & (2412) & (4064) & (228) & (1290) & (1761) & $(271)$ & (1109) & (931) & $(435)$ \\
\hline \multirow[t]{2}{*}{ Calliope } & 13 & 39 & 2 & 14 & 20 & 1 & 2 & 1 & 0 \\
\hline & $(473)$ & (214) & (49) & (154) & (170) & (12) & (28) & (2) & (0) \\
\hline \multirow[t]{2}{*}{ Burnett } & 24 & 178 & 9 & 47 & 69 & 8 & 26 & 5 & 0 \\
\hline & (470) & (786) & (137) & (398) & (313) & (55) & (156) & $(385)$ & (4) \\
\hline \multirow[t]{2}{*}{ Mary } & 17 & 732 & 11 & 253 & 328 & 27 & 61 & 12 & 2 \\
\hline & (1000) & (1466) & (206) & (727) & (756) & (84) & (168) & $(523)$ & (13) \\
\hline
\end{tabular}




\section{ACKNOWLEDGEMENT}

The model simulations, and the atmospherically-corrected satellite products, were developed as part of the eReefs project, a public-private collaboration between Australia's leading operational and scientific research agencies, government, and corporate Australia. We thank the many colleagues involved in developing the eReefs model, particularly Philip Gillibrand, Richard Brinkman, Cedric Robillot and Andy Steven.

\section{REFERENCES}

Baird, M. E., N. Cherukuru, E. Jones, N. Margvelashvili, M. Mongin, K. Oubelkheir, P. J. Ralph, F. Rizwi, B. J. Robson, T. Schroeder, J. Skerratt, A. D. L. Steven, and K. A. Wild-Allen (2016). Remote-sensing reflectance and true colour produced by a coupled hydrodynamic, optical, sediment, biogeochemical model of the Great Barrier Reef, Australia: comparison with satellite data. Env. Model. Software 78, 79-96.

Brinkman, R., H. Tonin, M. Furnas, B. Schaffelke, and K. Fabricius (2014). Targeted analysis of the linkages between river runoff and risks for crown-of-thorns starfish outbreaks in the Northern GBR. Technical report, Australian Institute of Marine Science.

Collier, C. J., M. Waycott, and L. J. McKenzie (2012). Light thresholds derived from seagrass loss in the coastal zone of the northern Great Barrier Reef, Australia. Ecol. Indic. 23, 211-219.

De'ath, D. G., J. M. Lough, and K. E. Fabricius (2009). Declining coral calcification on the Great Barrier Reef. Science 323, 116-119.

Devlin, M., E. da Silva, C. Petus, A. Wenger, D. Zeh, D. Tracey, J. Alvarez-Romero, and J. Brodie (2013). Combining in-situ water quality and remotely sensed data across spatial and temporal scales to measure variability in wet season chlorophyll-a: Great Barrier Reef lagoon (Queensland, Australia). Ecological Processes 2, 31 .

Devlin, M., C. Petus, E. da Silva, D. Tracey, N. Wolff, J. Waterhouse, and J. Brodie (2015). Water quality and river plume monitoring in the Great Barrier Reef: An overview of methods based on ocean colour satellite data. Remote sensing 7, 12909-12941.

Furnas, M. (2003). Catchments and corals: terrestrial runoff to the Great Barrier Reefs. Technical report, Australian Institute of Marine Science, Queensland, 334 p.

Gillibrand, P. A. and M. Herzfeld (2016). A mass-conserving advection scheme for offline simulation of tracer transport in coastal ocean models. Env. Model. Soft. 101, 1-16.

Gumley, L., J. Descloitres, and J. Shmaltz (2010). Creating reprojected true color MODIS images: A tutorial, Tech. Rep 1.0.2, 17 pp. Technical report, Univ. of Wisconsin, Madison.

Herzfeld, M. (2015). Methods for freshwater riverine input into regional ocean models. Ocean Model. 90, 1 15.

Herzfeld, M., J. Andrewartha, M. Baird, R. Brinkman, M. Furnas, P. Gillibrand, M. Hemer, K. Joehnk, E. Jones, D. McKinnon, N. Margvelashvili, M. Mongin, P. Oke, F. Rizwi, B. Robson, S. Seaton, J. Skerratt, H. Tonin, and K. Wild-Allen (2016). eReefs Marine Modelling: Final Report, CSIRO, Hobart 497 pp. http://www.marine.csiro.au/cem/gbr4/eReefs_Marine_Modelling.pdf rm. Technical report.

Herzfeld, M. and P. Gillibrand (2015). Active open boundary forcing using dual relaxation time-scales in downscaled ocean models. Ocean Model. 89, 71-83.

Margvelashvili, N., M. Herzfeld, F. Rizwi, M. Mongin, M. Baird, E. Jones, B. Schaffelke, E. King, and T. Schroeder (2016). Emulator-assisted data assimilation in complex models. Ocean Dyn. 66, 1109-1124.

Mongin, M., M. E. Baird, B. Tilbrook, R. J. Matear, A. Lenton, M. Herzfeld, K. A. Wild-Allen, J. Skerratt, N. Margvelashvili, B. J. Robson, C. M. Duarte, M. S. M. Gustafsson, P. J. Ralph, and A. D. L. Steven (2016). The exposure of the Great Barrier Reef to ocean acidification. Nature Communications 7, 10732.

Schroeder, T., M. J. Devlin, V. E. Brando, A. G. Dekker, J. E. Brodie, L. A. Clementson, and L. McKinna (2012). Inter-annual variability of wet season freshwater plume extent into the Great Barrier Reef lagoon based on satellite coastal ocean colour observations. Mar. Poll. Bull. 65, 210-223. 